Revista Destaques Acadêmicos, Lajeado, v. 13, n. 2, 2021. ISSN 2176-3070

DOI: http://dx.doi.org/10.22410/issn.2176-3070.v13i2a2021.2935

http://www.univates.br/revistas

\title{
A INTIMAÇÃO EXTRAJUDICIAL POR HORA CERTA DO DEVEDOR FIDUCIÁRIO: TEORIA E PRÁTICA NO REGISTRO DE TÍTULOS E DOCUMENTOS
}

\author{
Gabriel Delving Ely ${ }^{1}$, Maristela Juchum²
}

\begin{abstract}
Resumo: A pesquisa visa ao estudo do procedimento de execução extrajudicial do devedor fiduciário em sede de Registro de Títulos e Documentos, em delegação pelo Registro de Imóveis competente. Objetiva-se apresentar os impactos ao devedor inadimplente trazidos pelo procedimento executivo, bem como a maneira como o mesmo se processa, e o caminho percorrido até a satisfação do crédito pelo credor. Para tanto, estudam-se o instituto da alienação e propriedade fiduciárias e a sua utilização em financiamento imobiliário; o procedimento da notificação extrajudicial em Registro de Títulos e Documentos, e a prática da utilização do ato notificatório como meio de intimação do devedor fiduciário, sobretudo quando realizado este através do rito da intimação por hora certa, em aplicação subsidiária do Código de Processo Civil, concluindo-se acerca da relevância jurídica do referido procedimento, sua conveniência na concessão de crédito imobiliário, e a cautela que a sua prática demanda do registrador público. Faz-se isto valendo-se de pesquisa qualitativa, instrumentada bibliograficamente, e através do método dedutivo.
\end{abstract}

Palavras-chave: Registros públicos. Notificação extrajudicial. Alienação fiduciária.

\section{INTRODUÇÃO}

O financiamento imobiliário tem sido, e em maior incidência desde o lançamento do programa "Minha Casa, Minha Vida", uma alternativa àqueles que sonham com a casa própria, mas não têm condição de adquirir um imóvel à vista, ou parcelado diretamente com o vendedor. Nesses casos, de modo a garantir a dívida contraída, é comum que se coloque como garantia

1 Acadêmico do Curso de Direito da Universidade do Vale do Taquari - UNIVATES. Escrevente autorizado do Tabelionato e Ofício dos Registros Especiais de Lajeado/RS. gabriel.ely@ universo.univates.br

2 Doutora em Letras pela Universidade Federal do Rio Grande do Sul (UFRGS). Professora da disciplina de Leitura e Produção de Textos II, da Universidade do Vale do Taquari UNIVATES. juchum@univates.br 
do financiamento o próprio bem financiado, em alienação fiduciária. Contudo, o que à primeira vista aparenta ser uma via para a realização do sonho da casa própria pode - frise-se: pode, de modo que não se trata o presente de uma crítica ao instituto - vir a se tornar um pesadelo, a partir do momento em que o devedor não consegue pagar as parcelas pactuadas. Isso porque o instituto da alienação fiduciária, segundo as faculdades reconhecidas pela Lei 9.514/97, permite à instituição financeira credora a consolidação da propriedade sobre o imóvel em face do inadimplemento do contrato (art. 26).

Cabe ressaltar que, entre a inadimplência e a efetiva consolidação da propriedade, a lei demanda à instituição que notifique o devedor a respeito de suas pendências, constituindo-o em mora, e outorgando prazo para a quitação, o que se dá pelo procedimento de notificação extrajudicial - a ser promovida pelos Ofícios de Registro de Imóveis e, por vezes, de Títulos e Documentos que, por sua vez, em determinadas condições, pode-se dar pelo rito ficto da "hora certa", objeto deste estudo.

É de significativa pertinência o estudo acerca da utilização da notificação extrajudicial como forma de constituição em mora do devedor fiduciário, posto que se refere a um procedimento de constrição à propriedade - que, por vezes, recai sobre um bem de família - cujo processamento se dá em sua integralidade pela via extrajudicial. Neste sentido, tem-se a constituição em mora e, após o decurso do prazo, sem o adimplemento da dívida, a possibilidade de consolidação da propriedade fiduciária em favor da instituição financeira credora, de modo que sem qualquer trâmite além, seja o imóvel alienado encaminhado a leilão.

Destarte, face à magnitude dos efeitos que os atos registrais podem influir sobre o direito de propriedade, compete o estudo do instituto da intimação extrajudicial - sobretudo quando realizada sob a via ficta da "hora certa", em aplicação subsidiária dos dispositivos do art. 252 e subsequentes do Código de Processo Civil - de modo a esclarecerem-se seus pressupostos e regulações, elucidando-se equivocadas concepções do público em geral e evitando-se injustiças por parte da eventual incorreta aplicação do procedimento por parte da autoridade registral, bem como garantindo-se os direitos de ambos, credor e devedor fiduciários, anteriormente contratados.

À luz do exposto, presta-se este trabalho à identificação dos dispositivos legais regulatórios dos institutos alhures apresentados, bem como de sua práxis e problemáticas, fazendo uso do método dedutivo, em pesquisa essencialmente qualitativa por meio de instrumentais bibliográficos.

O presente artigo é dividido em três seções, nas quais discorre-se a respeito do instituto da Alienação Fiduciária, e do procedimento de intimação extrajudicial, adentrando, após, no procedimento específico da notificação extrajudicial do devedor fiduciário, com ênfase naquela realizada por meio de "intimação por hora certa". 


\section{DA ALIENAÇÃO FIDUCIÁRIA DE BEM IMÓVEL}

Adentrando à temática deste trabalho, fundamental a caracterização do instituto da alienação fiduciária, mediante a apresentação de seu conceito e arcabouço normativo, e vislumbrando a constituição deste gravame sobre a propriedade imobiliária, o que adiante se faz.

Emerge a alienação fiduciária no ordenamento jurídico, no que se refere ao setor imobiliário, com a edição da Lei Federal 9.514/97, que dispõe sobre o Sistema de Financiamento Imobiliário nacional. Referida lei, em seu art. 17, IV, reconheceu a constituição de alienação fiduciária de coisa imóvel como meio de garantia de operações de financiamento imobiliário, trazendo, nos arts. 22 e subsequentes, o seu regramento específico.

Para melhor compreensão do instituto de alienação fiduciária em garantia de financiamento imobiliário, faz-se necessário adentrar-se ao conceito da propriedade fiduciária, pela qual perfaz-se o gravame em estudo. Neste sentido, tem-se por propriedade fiduciária a entrega, mediante negócio jurídico formal e bilateral, da posse indireta ${ }^{3}$ e propriedade resolúvel ${ }^{4}$ do bem objeto do contrato (FARIAS, ROSENVALD, BRAGA NETTO, 2018). Não obstante haja a possibilidade de constituição de propriedade fiduciária sobre bens móveis - cujo regramento toma fulcro no art. 1.361 do Código Civil -, a modalidade em estudo - referente a bens imóveis - é regrada em lei especial, qual seja, a Lei 9.514/97, termos em que, serão aplicáveis também a esta modalidade as disposições da codificação civil tão somente quando não forem estas contrárias à lei específica (art. 1.368-A, CC).

Na lição de Melhim Chalhub (2018), caracteriza-se a alienação fiduciária de imóvel como garantia de um negócio jurídico, in casu, o financiamento imobiliário, que, acessoriamente, assegurará o seu pagamento. Em igual sentido, esclarece Mário Pazutti Mezzari:

A alienação fiduciária em garantia não tem por finalidade precípua a transmissão da propriedade, embora esta seja de sua natureza. A transferência do domínio do bem ao credor não é o fim colimado pelas partes, mas um meio de garantir o credor contra a inadimplência do devedor. (1998, p. 13)

Funda-se, pois, como garantia real, firmada, como já mencionado, em negócio jurídico formal, o qual se pode revestir sob a forma particular ou pública (GONÇALVES, 2018). Note-se que, neste caso, muito embora refira-se

3 Indireta, posto que se reserva ao devedor a efetiva posse e o direito de gozo sobre o bem, ainda que alienado.

4 Resolúvel, haja vista tratar-se de propriedade cujo termo encontra-se necessariamente datado a findar-se, conforme previsão do contrato que a constitui. 
a instituição de constrição à propriedade imobiliária, faculta-se a sua outorga em escritura pública, termos em que o contrato particular que a pactua possui força de instrumento público e constitui título passível de ingresso no Registro de Imóveis (LOUREIRO, 2018).

Neste liame, vez que instituída a propriedade fiduciária sobre o imóvel, torna-se o credor (fiduciante) detentor da posse indireta do bem, enquanto o devedor (fiduciário) detém a posse direta e o domínio sobre o mesmo, porquanto perdurar o contrato e permanecer o mesmo em cabal cumprimento. Entretanto, em não havendo o cumprimento pontual do devedor para com suas obrigações decorrentes do financiamento contratado, caberá ao credor usar de suas faculdades reivindicatórias, de modo a compelir o fiduciário a adimplir o devido, ou encerrar o contrato através da consolidação da propriedade fiduciária, observado o rito trazido pela Lei 9.514/97, retirando o devedor da posse direta do bem, resolvendo-se a propriedade que antes era ficta em real a favor do fiduciante (CHALHUB, 2006). Dito procedimento dá-se por meio da cobrança extrajudicial, a ser realizada pelo Ofício de Registro de Imóveis (RI), a requerimento do credor, facultando-se ao registro imobiliário (LOUREIRO, 2018) a requisição de tal serviço ao Registro de Títulos de Documentos (RTD) da circunscrição registral competente, o qual a promoverá sob a forma de notificação extrajudicial, a qual adiante se estuda, adentrandose, posteriormente, na temática específica do que se refere à notificação do devedor fiduciário.

\section{DA NOTIFICAÇÃO EXTRAJUDICIAL}

Superada a questão da alienação fiduciária, pertinente a ilustração do rito de notificação do devedor fiduciário no descumprimento de suas obrigações, pelo que se elucida a seguir o procedimento de notificação extrajudicial nos cartórios de Registro de Títulos e Documentos no Brasil.

\subsection{Os cartórios de Registro de Títulos e Documentos: aspectos gerais e normativos}

Outorgada ao titular (ou Oficial) através de concurso público de provas e títulos, a atividade notarial e registral encontra respaldo no art. 236 da Constituição Federal, sendo estatuída pela Lei Federal 8.935/94 (Lei dos Notários e Registradores ou Lei dos Cartórios), que, em seu art. $3^{\circ}$, qualifica o exequente da função como "profissional de direito, dotado de fé pública, a quem é delegado o exercício da atividade notarial e registral". Tem-se que ao registrador público cabe a função de conferir aos atos e negócios jurídicos das partes a devida publicização, tornando aquilo que ocorrera ou fora contratado oponível perante o ordenamento. Esta faculdade de publicidade é inerente à função registral, e deriva do instituto da fides publicae investida pelo poder delegante ao delegatário (CENEVIVA, 2010). 
Mais especificamente, ao Registro de Títulos e Documentos, ou Oficial de Registro de Títulos e Documentos, cujo regramento procedimental encontra base no art. 127 e subsequentes da Lei dos Registros Públicos (Lei 6.015/73 LRP), compete, na lição de Loureiro:

Assegurar a autenticidade, segurança, publicidade e eficácia dos atos e negócios jurídicos, conferindo oponibilidade [...] de direitos e situações jurídicas constituídos em contratos, provando a existência e a data de documentos particulares e promovendo a conservação perpétua de seu conteúdo. (2018, p. 461)

Nesta linha, caberá ao RTD o registro dos títulos arrolados nos incisos do art. 127 da LRP, dentre os quais, instrumentos particulares em geral, o penhor comum de coisa móvel, e o contrato de parceria agrícola ou agropecuária. Complementa-se que na seara do registrador de títulos e documentos está a publicização de documentos cujo registro não seja de competência de outra modalidade cartorária (Registros de Imóveis, Pessoas Jurídicas, de Pessoas Naturais,...), pelo que é chamada a sua abrangência de "competência supletiva" (CENEVIVA, 2010, p. 362), por força do parágrafo único do art. 127 da Lei dos Registros Públicos, que traz a faculdade de inscrição em RTD de quaisquer documentos "não atribuídos expressamente a outro ofício".

Igualmente ao Registrador de Títulos e Documentos compete a prática de notificar, a respeito dos instrumentos por ele registrados, pessoas indicadas pelo apresentante dos respectivos títulos (CENEVIVA, 2010). Tratase do procedimento de notificação extrajudicial, através do qual o registrador promove o conhecimento da pessoa indicada pelo apresentante a respeito do teor do documento registrado - sobre a qual mais especificamente disserta-se a seguir.

\subsection{A notificação extrajudicial}

Trazida pelo art. 160 da Lei dos Registros Públicos, a notificação extrajudicial é meio pelo qual o registrador procede à cientificação de determinada pessoa, indicada pelo apresentante do título, do inteiro teor do documento registrado (MONTES JUNIOR, 2014). Neste sentido, vez que registrado o documento, o registrador - ou um preposto designado diligenciará de modo a notificar a parte indicada da existência do referido registro acerca do referido lançamento em sua serventia, procedimento este que culminará na devolução ao solicitante do serviço de uma certidão narrativa de cumprimento, na qual descreverá o Oficial como se deu a notificação, ou mesmo justificará o inexitoso encerramento da mesma (CENEVIVA, 2010).

Importante ressaltar a necessidade de limitarem-se as atividades do registrador às margens territoriais correspondentes à sua circunscrição registral, em atenção ao Princípio da Territorialidade (LOUREIRO, 2018), 
o que impacta diretamente no procedimento de notificação, posto que não poderá determinado RTD diligenciar para além dos limites geográficos de sua competência. Inobstante tal limitação, nada impede que o registrador recepcione e registre o documento destinado a cumprimento em outra circunscrição, termos em que deverá ele remetê-lo ao oficial competente (art. 160, LRP), que por sua vez igualmente registrará o documento em seus títulos, e procederá à notificação, devolvendo ao registrador originário a respectiva certificação.

Em virtude de ser a notificação extrajudicial um meio consolidado no direito brasileiro como prova da cientificação do teor do documento ao notificado, muito se usa este rito para, entre outros fins, a constituição em mora do devedor de determinada obrigação, dada a segurança jurídica a ele atrelada, pelo que se vê adiante.

\subsection{A notificação extrajudicial como meio de prova da constituição em mora}

Como anteriormente já fora trazido, em virtude de ser meio idôneo, admitido em direito, de comprovação do efetivo conhecimento do conteúdo do registro objeto da notificação (LOUREIRO, 2018), tem-se a notificação extrajudicial como uma recorrente forma de comunicação ao devedor de determinada obrigação acerca de seus débitos para com seu credor. Derivase tal concepção da ideia de ser o RTD, na pessoa de seu delegatário, dotado de fé-pública, termos em que a certificação do cumprimento da notificação será, perante o ordenamento jurídico, dotada de presunção de veracidade (CENEVIVA, 2010), o que implica em segurança ao credor no que se refere ao conhecimento dos termos remetidos ao devedor ${ }^{5}$. Exemplo de cabimento da notificação extrajudicial como meio probatório da constituição em mora do devedor é a situação trazida pela Lei 9.514/97, notadamente do devedor fiduciário, pelo que se aborda adiante.

\section{DA “INTIMAÇÃO” EXTRAJUDICIAL DO DEVEDOR FIDUCIÁRIO}

Superada a conceituação acerca da propriedade e alienação fiduciárias, bem como do procedimento de notificação extrajudicial em sede de Registro de Títulos e Documentos, cabe analisar a aplicabilidade de referido procedimento na execução extrajudicial (SANTOS, 2018) do devedor em financiamento imobiliário garantido por alienação fiduciária, forte à Lei 9.514/97, precipuamente a seu art. 26 e dispositivos. Em virtude de sua natureza, similar à execução de título em sede de processo judicial, vale-se a doutrina da expressão

5 Neste liame, perfeitamente admissível a ideia de que independe a efetivação do ato notificatório do lançamento da assinatura do notificado para o recebimento da carta, termos em que ao registrador facultar-se-á afirmar ter o notificado tomado plena ciência do teor do documento, se diante de dele ou de preposto seu, o mesmo o tenha lido e tomado conhecimento de seus termos. 
"execução extrajudicial" (CETRARO, 2018; MARTINEZ, 2008; SANTOS, 2018), de modo a traçar um paralelo com o processo de execução, regido pelo Código de Processo Civil. Referida linha encontra reforço quando lida à luz da Lei 13.465/17, que alterou a Lei 9.514/97, permitindo a aplicação subsidiária da lei processual no procedimento de notificação do devedor fiduciário, autorizando a realização do ato intimatório sob o rito da "hora certa", nos termos dos arts. 252 a 254 do CPC, sobre a qual adiante se aborda.

Desnecessária a elucidação de como dá-se o procedimento notificatório em Títulos e Documentos, objeto da seção anterior deste artigo, cabe breve menção ao seu regramento trazido pela Lei 9.514/97, aplicável à notificação extrajudicial quando de intimação de débito fiduciário tratar-se. A esse respeito, Luiz Guilherme Loureiro:

Vencida e não paga a dívida, o devedor (fiduciante) deve ser constituído em mora, mediante intimação feita pelo oficial do Registro de Imóveis, a pedido do credor fiduciário. Na intimação constará o prazo de 15 dias para pagamento das prestações vencidas e as que se vencerem até a data do pagamento [...]. Deverá ser paga ainda a despesa de cobrança e da intimação. (2018, p. 852)

Note-se que o autor supra faz menção ao cumprimento da intimação pelo registrador de imóveis. Trata-se da regra trazida pelo art. $26, \S 3^{\circ}$, da Lei 9.514/97, haja vista que, em virtude de tratar-se de procedimento relacionado à propriedade imobiliária, reza a lógica processe-se o mesmo perante o Registro de Imóveis. Não obstante, o mesmo dispositivo traz a faculdade de, após a devida prenotação do requerimento do credor fiduciário em sede de registro imobiliário, requeira o Registrador de Imóveis ao Registrador de Títulos e Documentos que proceda à intimação, prática esta bastante recorrente, dada a estrutura que já possui o RTD em virtude das demais notificações extrajudiciais, de sua competência forte ao art. 160 da LRP - e incomum à rotina do Cartório de Registro de Imóveis.

Igualmente interessante anotar-se a questão da terminologia adotada, sobretudo no que se refere ao cumprimento da intimação pelo RTD. Isto porque gira a práxis do Cartório de Títulos e Documentos em torno do cumprimento de notificação extrajudicial, regrada pela Lei dos Registros Públicos e os códigos de normas estaduais acerca da atividade registral. Entretanto, a Lei 9.514/97, e, por conseguinte, a doutrina (CETRARO, 2018; LOUREIRO, 2018; MARTINEZ, 2008; SANTOS, 2018) adotam o termo intimação para o ato de tomada de ciência do devedor acerca do débito - suscetível, inclusive, à confusão com a intimação em sede judicial, que é ato de comunicação processual (DONIZETTI, 2018).

De toda sorte, sob a égide do art. 26 e dispositivos da Lei 9.514/97, realizará o registrador - ou escrevente por ele designado, vide art. $160 . \S 2^{\circ}$, LRP - a notificação, ou intimação, do devedor, de modo a constituí-lo em mora. Vez intimado, outorga-lhe o prazo de quinze dias para o adimplemento do débito 
(purga da mora), devidamente atualizado e com as demais despesas alhures mencionadas, junto ao Cartório de Registro de Imóveis (ainda que a intimação se tenha dado através do RTD, frise-se), que encerrará o procedimento executivo. Há também a possibilidade de restar infrutífera a intimação pessoal, caso em que o oficial não logra êxito em localizar a pessoa a ser intimada, por encontrar-se a mesma em local incerto ou não sabido, termos em que caberá a realização da referida intimação por edital, exclusivamente em sede de Registro de Imóveis (MARTINEZ, 2008). Neste caso, o oficial de RTD expedirá certidão narrativa das diligências e dos motivos que lhe impediram de cumprir a intimação. Note-se que, a partir do momento em que se encerra a intimação pessoal - seja negativa ou positiva -, encerra-se igualmente a participação do RTD no procedimento, devolvendo-se ao RI a certificação do cumprimento do ato.

\subsection{A intimação por hora certa do devedor fiduciário}

Como antes mencionado, o procedimento de intimação por Carta de Notificação é de caráter pessoal, do que se pode depreender, à luz da doutrina processual lida em analogia, deve ser realizada diretamente à pessoa do devedor, procurador devidamente constituído, ou mesmo do presentante, quando tratarse de devedor pessoa jurídica (WAMBIER; ALMEIDA; TALAMINI, 2006). Neste sentido, justifica-se restar negativo o ato notificatório do devedor não localizado pelo oficial em diligência, posto encontrar-se inviabilizada a intimação pessoal do mesmo. Entretanto, há casos em que a má-fé do devedor, em escusar-se de receber a intimação - propositadamente inviabilizando a constituição em mora - fica nítida ao registrador no cumprimento das diligências. Para estes casos, a Lei 13.465/17 trouxe uma alternativa à intimação pessoal: a intimação por hora certa, em aplicação subsidiária do Código de Processo Civil. Tratase de inovadora e louvável ferramenta no combate à inadimplência e à má-fé contratual, mas cujo uso demanda especial cautela do delegatário de serviço extrajudicial, dados os impactos que o seu imprudente emprego pode trazer ao direito fundamental à propriedade do devedor. Explica-se: a intimação por hora certa remete ao ato da citação por hora certa, cuja disciplina legal encontra base nos arts. 252 a 254 do CPC, segundo os quais, quando o Oficial de Justiça, depois de, no mínimo duas tentativas pessoais, e motivadamente suspeitando de ocultação do réu, de modo a evadir-se do chamamento processual, agenda com vizinho, familiar ou conhecido do mesmo - que deverá entregar a contrafé do aviso ao réu - um horário para o dia útil imediatamente subsequente àquele para a realização da intimação, que se dará por cumprida ainda que sem a presença do réu. Funda-se caso de citação ficta, haja vista que a ciência do réu 
é presumida, e não absoluta - ao contrário do que se tem na de caráter pessoal (DIDIER, 2019) .

Neste liame, a faculdade de aplicação subsidiária da hora certa processual na execução extrajudicial do devedor fiduciário cria a intimação por hora certa, a realizar-se, de regra, exclusivamente em sede extrajudicial, posto tratar-se a intimação em processo judicial de ato de comunicação de prosseguimento do feito, o qual não ensejaria tal procedimento. Destarte, detendo o oficial fundadas informações a respeito do paradeiro do devedor, bem como munido de convincentes indícios de encontrar-se o mesmo residindo no local de cumprimento da intimação, e estar o devedor furtando-se de recebê-lo, ou mesmo de atender aos pedidos de comparecimento ao Ofício por ele deixados a cada diligência, iniciará, motivadamente, o procedimento por hora certa, que poderá, por sua vez, levar à intimação ficta do devedor fiduciário, que será comunicado, no prazo máximo de dez dias da data da intimação, por correio com comprovação de recebimento, da realização da intimação (art. 254, CPC).

\subsection{O efeito da intimação do devedor fiduciário e a intimação por hora certa}

Como já trazido anteriormente, uma vez intimado o devedor, se concede a ele o prazo para a purga da mora - tal disposição, que é expressamente prevista no contrato por ele assinado, é igualmente aplicável aos casos em que se realiza a intimação pelas vias da hora certa, vez que não faz a lei caso acerca de distinções de prazo ou procedimento para com a intimação pessoal ou ficta, após cumprida. Decorrido o prazo concedido e não havendo o adimplemento do devedor, o Registro de Imóveis prossegue com a execução extrajudicial do devedor, resultando na consolidação da propriedade em favor do credor em face do inadimplemento contratual (LOUREIRO, 2018). Eis o porquê de demandar-se tamanha cautela no uso da hora certa: por ser meio ficto, de intimação presumida, o juízo do registrador sobre a suspeita de ocultação do intimando deve ser muito bem justificado, posto que se lida aqui, na grande maioria das vezes, com a residência familiar do devedor. Neste liame, uma eventual intimação por hora certa realizada sem que houvesse ocultação do devedor - ou seja, o devedor não fica sabendo da realização da intimação e está agindo de boa-fé, posto acreditar não haver sido constituído em mora - pode levar à constrição de sua habitação sem que sequer tome conhecimento antes da tomada do bem. Nestes termos, tem-se que a função do registrador público é garantir segurança jurídica nos atos realizados sob a sua tutela, e isto se aplica para ambas as partes, devedor e credor.

6 Outro exemplo de citação ficta é a realizada por edital. 


\section{CONSIDERAÇÕES FINAIS}

Ante o exposto no decorrer deste texto, tem-se que, muito embora seja o meio da alienação fiduciária em garantia um meio de viabilizar a concretização de um sonho de aquisição por parte de grande parte da população, trata-se de situação jurídica complexa, e que demanda verdadeira cautela em sua condução por parte de ambos os contratantes, credor e devedor. Outrossim, em caso de inadimplemento do contrato, especial atenção deve ser destinada pelo credor quando da execução do débito, em meio extrajudicial, de modo a garantir a efetividade do procedimento, observando-se os requisitos legais, de forma que não seja o mesmo eivado de anulabilidade.

De mesmo modo, e com maior ênfase a partir deste estudo, tem-se que ao registrador de imóveis e de títulos e documentos (objeto desta pesquisa), compete a inarredável atenção ao rito do procedimento executivo, atuando como guardião dos direitos tanto do credor - que o busca de modo a ver satisfeito seu crédito - quanto do devedor - que por eventual imprudência registral pode vir a achar-se sem habitação. A execução extrajudicial objeto deste estudo é meio célere de cobrança, e alternativa eficaz de garantia em financiamento imobiliário, e que, justamente por isso, exige rigor em seu exercício. Mais ainda, no que se refere à realização da intimação do devedor através do procedimento da hora certa, meio ficto de comunicação ao executado, que faz uso da presunção de sua ciência acerca do débito para dar prosseguimento ao procedimento. Não à toa dotado de rígida regulamentação legal, é meio de intimação que se dará - obviamente, mediante motivação - através do juízo do registrador a respeito das suspeitas de ocultação do intimado, situação na qual, dados os impactos à moradia do devedor, não há espaço para incertezas.

Isso posto, conclui-se que o chamamento do devedor fiduciário por meio extrajudicial, sobretudo em rito de intimação por hora certa, encontrase no ordenamento jurídico como inovação legislativa, de modo a garantir a efetivação da função social do contrato, e ver satisfeitos os direitos e obrigações de ambos credor e devedor. Contudo, dada a sua relevância social e jurídica, demanda plena consciência do registrador público que executa o procedimento em tela, de modo a não lesar o devedor de boa-fé, tampouco deixar desamparado o credor em pleno exercício de seus direitos.

\section{REFERÊNCIAS}

BRASIL. Código Civil. In: Vade Mecum Saraiva. 23. ed. São Paulo: Saraiva, 2017. 2017.

. Código de Processo Civil. In: Vade Mecum Saraiva. 23. ed. São Paulo: Saraiva, . Constituição da República Federativa do Brasil. In: Vade Mecum Saraiva. 23. ed. São Paulo: Saraiva, 2017. 
Lei 6.015, de 31 de dezembro de 1973. Dispõe sobre os registros públicos e dá outras providências. In: Vade Mecum Saraiva. 23. ed. São Paulo: 2017.

. Lei 8.935, de 18 de novembro de 1994. Regulamenta o art. 236 da Constituição Federal, dispondo sobre serviços notariais e de registro. In: Vade Mecum Saraiva. 23. ed. São Paulo: 2017.

Lei 9.514, de 20 de novembro de 1997. Dispõe sobre o Sistema de

Financiamento Imobiliário, institui a alienação fiduciária sobre coisa imóvel e dá outras providências. In: Vade Mecum JusPodivm. 4. ed. Salvador: 2018.

. Lei 13.465, de 11 de julho de 2017. Dispõe sobre a regularização fundiária rural e urbana, sobre a liquidação de créditos... In: Vade Mecum JusPodivm. 4. ed. Salvador: 2018.

CENEVIVA, Walter. Lei dos registros públicos comentada. 20. ed. São Paulo: Saraiva, 2010 .

CETRARO, José Antonio. A execução extrajudicial no SFH: do Decreto-lei 70/66 à Lei 9.514/97. Revista de Direito Imobiliário, São Paulo, SP, v. 84/2018, p. 427-439, 2018.

CHALHUB, Melhim Namem. Negócio fiduciário. 3. ed. Rio de Janeiro: Renovar, 2006. Alienação fiduciária de bens imóveis: 20 anos da vigência da Lei 9.514/1997. Revista de Direito Imobiliário, São Paulo, SP, v. 84/2018, p. 495-531, 2018.

DIDIER, Junior, Fredie. Curso de direito processual civil: introdução ao direito processual civil, parte geral e processo de conhecimento. 21. ed. Salvador: Juspodivm, 2019.

DONIZETTI, Elpídio. Curso didático de direito processual civil. 21. ed. São Paulo: Atlas, 2018.

GONÇALVES, Carlos Roberto. Direito civil brasileiro: direito das coisas. v. 5. 13. ed. São Paulo: Saraiva, 2018.

LOUREIRO, Luiz Guilherme. Registros públicos: teoria e prática. 9. ed. Salvador: Juspodivm, 2018.

MARTINEZ, Sérgio Eduardo. Alienação Fiduciária de Imóveis. In: PAIVA, João Pedro Lamana; TIMM, Luciano Benetti; TUTIKIAN, Cláudia Fonseca (Orgs.). Novo Direito Imobiliário e Registral. São Paulo: Quartier Latin, 2008. p. 480-517.

MEZZARI, Mario Pazutti. Alienação fiduciária: da Lei 9.514, de 20-11-1997. São Paulo: Saraiva, 1998.

MONTES JUNIOR, Valdomiro. Comentário ao art. 160 da Lei de Registros Públicos. In: ALVIM NETO, José Manuel Arruda; CLÁPIS, Alexandre Laizo; CAMBLER, 
Everaldo Augusto (Coords). Lei de registros públicos comentada: (Lei 6.015/1973). Rio de Janeiro: Forense, 2014. p. 449-459.

ROSENVALD, Nelson; FARIAS, Cristiano Chaves de; NETTO, Felipe Braga. Manual de Direito Civil. 3. ed. Salvador: JusPodivm, 2018.

SANTOS, Paulo Cesar Batista dos. Aspectos pontuais da execução extrajudicial na alienação fiduciária de bens imóveis. Revista de Direito Imobiliário, São Paulo, SP, v. 84/2018, p. 479-494, 2018.

WAMBIER, Luiz Rodrigues; ALMEIDA, Flavio Renato Correia de; TALAMINI, Eduardo. Curso avançado de processo civil: teoria geral do processo e processo de conhecimento. v. 1. 8. ed. São Paulo: Revista dos Tribunais, 2006. 